\title{
The Ureter, Ureterovesical Junction, and Vesical Trigone '
}

\author{
RUSSELL T. WOODBURNE \\ Department of Anatomy, The University of Michigan, \\ Ann Arbor, Michigan
}

\begin{abstract}
The musculature of the ureter has a layered arrangement in which the internal layer is mainly longitudinal and the external layer is largely circular. There is, however, intermingling and migration of fascicles between layers. At the passage of the ureter through the bladder wall this layering is lost and all fascicles become oriented longitudinally.

At the ureterovesical junction fibers of the detrusor muscle of the bladder, interspersed with delicate connective tissue, reflect onto the ureter over a distance to 2 to $3 \mathrm{~cm}$. This "sheath" of the ureter, as it has been designated, is a reflection of bladder wall muscle onto the ureter. At its passage through the bladder wall, the ureter is loose and an injectable space exists around it. This is properly termed "Waldeyer's separation" since he called attention to it in 1892.

Within the bladder, the ureteric wall flattens and widens, allowing the lumen to migrate to the surface to constitute the ureteral aperture at the angle of the vesical trigone. Delicate muscular decussations occur proximal and distal to the aperture.

Ureteric muscle mainly forms the vesical trigone. Most fascicles run to the midline and blend with those of the opposite side in the interureteric fold. Others spread through the trigone, its lateral margin being formed of somewhat more numerous fascicles directed toward the vesical orifice. Very few fibers actually descend into the urethra. The principal fixation of the ureter into the bladder is to the mucous membrane of the trigone area and to the deeper lying muscle and connective tissue.
\end{abstract}

\section{Ureter}

Relatively little attention has been paid recently to the structure of the ureter. The musculature is generally disposed in two layers; of these the inner one is longitudinal in orientation and the outer one is circular. This is the usual description encountered in most reports as far back as Henle (1856). Close observation of cross sections of the ureter, however, fails to confirm a sharp separation of these layers and gives the impression that fascicles of both layers are oblique and blend into one another (figs. 1 and 2). Such changes of direction indicate that the musculature is somewhat mesh-like in character. This was first noted by Sappey in 1889 who denied a layering of the ureter musculature. He noted that the muscle bundles continually change their direction and often transfer from one layer into the other. With these opposing views in mind a close study has been made of sections cut both longitudinally (fig. 2) and in cross section. It is concluded that there is a definite meshwork character of this musculature but that nevertheless a general orientation of inner longitudinal and outer circular layers may be said to pertain. Individual fascicles do transfer from one layer to another and many oblique fascicles are to be seen. Von Mollendorf ('30) also observed that study of horizontal sections of the ureteral wall shows the circular muscle to consist of more massive bundles than the internal layer, but he noted, too, that the bundles are abundantly interconnected layer to layer and that there are only extremely thin elastic networks.

Current accounts frequently state that there is an additional muscular layer at the lower end of the ureter. Sometimes this character is cited for the lower onethird of the tube. The fact is that in the lower 2 or $3 \mathrm{~cm}$ of the ureter, fascicles of bladder muscle reflect onto the ureter and gain attachment into its adventitia (fig. 3). This musculature is distinctly detrusor in character and has been shown by Waldeyer to be separated from the ureter itself by a small injectable space so that the

\footnotetext{
1 This investigation supported by U.S.P.H.S. research grant A 5747 .
} 


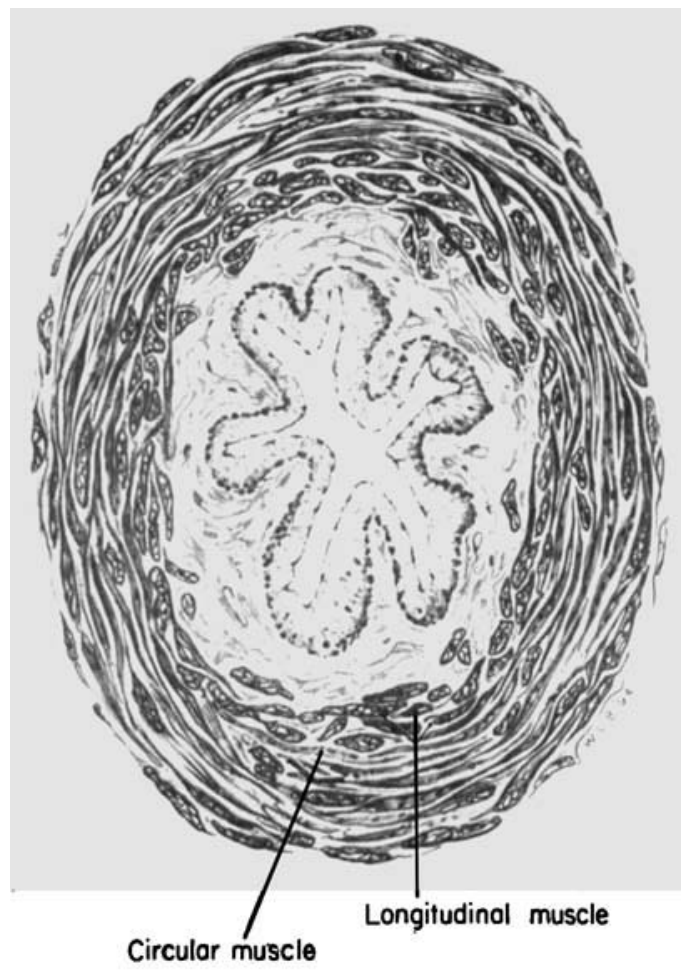

Fig. 1 Tissue map (drawing) of a cross section of the midlength of the human ureter.

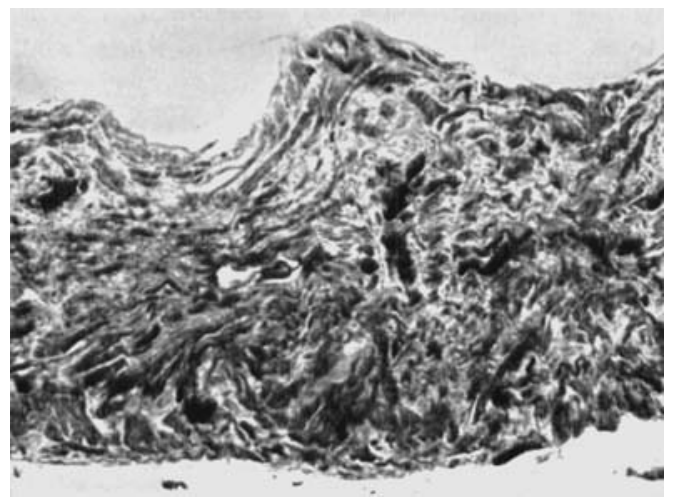

Fig. 2 Photograph of a horizontal section of a segment of the human ureter just superficial to its lumen. $\times 45$.

ureter remains free within this small enclosure.

\section{Ureterovesical junction}

In view of varying reports in the urological literature, it will be well to examine the ureterovesical junction of man more closely. Previous studies (Uhlenhuth, Hunter, and Loechel, '53; Hunter, '54; and Woodburne, '60 and '61) have emphasized that the bladder wall is composed of an irregular meshwork of coarse fascicles which are interspersed with relatively loose connective tissue. The layering of the bladder has been in some dispute through the years. Hunter ('54) showed that there is intermingling, interweaving, and shift of fascicles from level to level and from direction to direction. In tracing individual fascicles he found that they might change their direction, level in the bladder wall, and orientation as many as five times. While the concept of an irregular muscular meshwork is valid for the bladder wall in general, its posterior medial aspect exhibits vertical, longitudinally running bundles which, reaching the neck of the bladder, diverge around the base of the prostate. The divergence of this group of muscle fibers and its coverage of prostate laterally and anteriorly has been seen by many observers. Hutch et al., ('61) designates the more lateral longitudinal fascicles as "sling muscle" and says that they support the terminal ureter, being at right angles to it. I have not been able to confirm either the right-angled relation or the support function.

It is just lateral to the lateral border of this longitudinally arranged muscle that the ureter inserts itself in its passage through the bladder wall (fig. 3). As the ureter begins to penetrate the bladder wall the superficial fascicles medial to the ureter are elevated and fascicles both medial and lateral are forced aside for the passage of the ureter. On the medial side the diverging fascicles are principally of a deeper layer of muscle and disappear under the superficial layers both above and below the point of entrance of the ureter. Detrusor fascicles sweep onto the lower 2 or $3 \mathrm{~cm}$ of the ureter (fig. 3 ), prominently from below and somewhat less prominently from above. These are coarse fascicles of muscle identical in all respects to detrusor muscle all around them. Those fascicles which ascend to the ureter are predominantly from the more superficial musculature, the descending fascicles arise principally in the deeper parts of the wall. This investment of the ureter by 

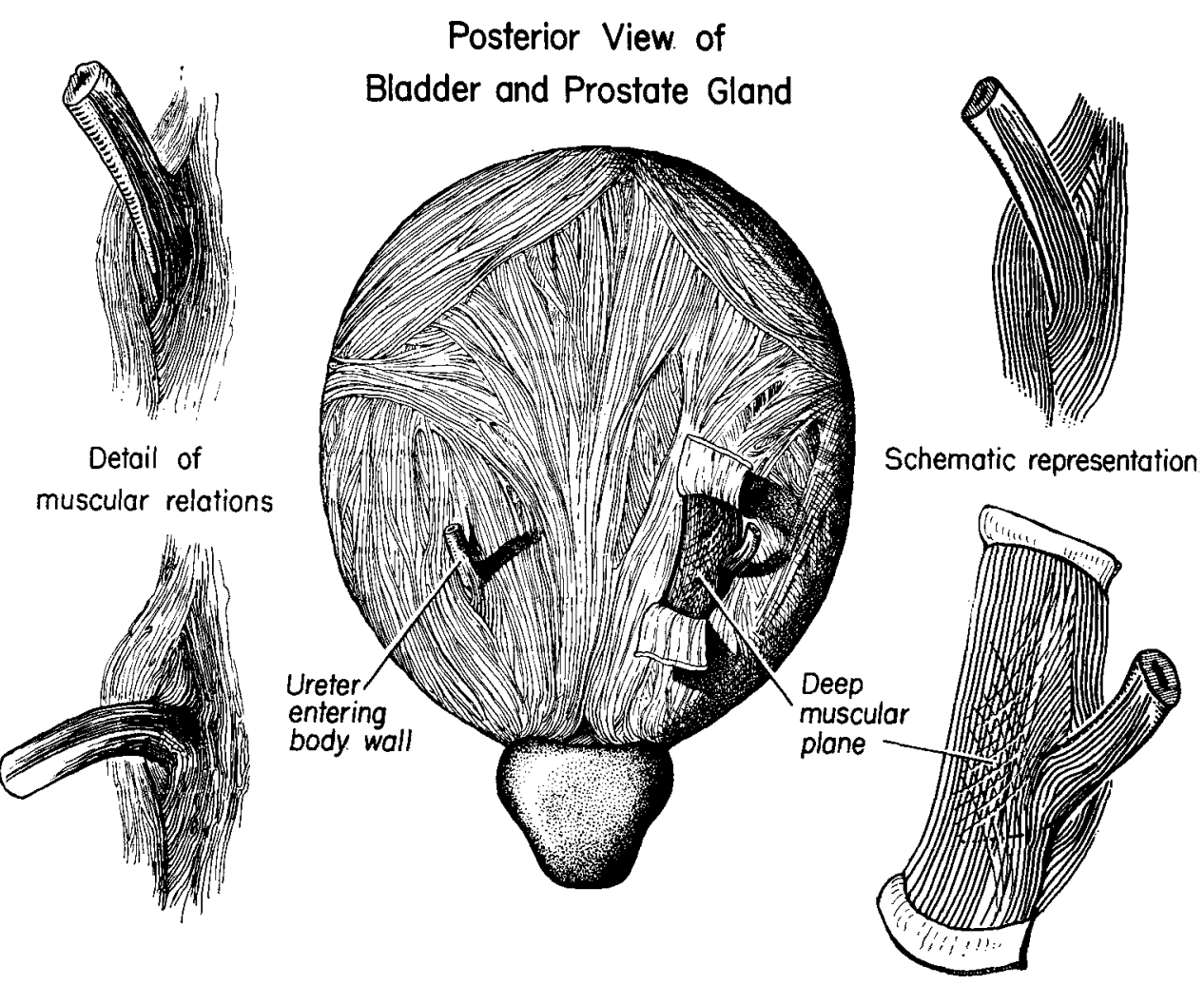

Fig. 3 Dissection of the terminal ureter and posterior aspect of the human bladder. (By permission of the Journal of Urology.)

detrusor muscle is evident upon dissection and is also seen in sections of the region in any plane (fig. 4). It is this which Cunningham ('64) speaks of as the sheath of the ureter and which appears to have been incorrectly designated Waldeyer's sheath by a number of authors. It is also perfectly evident, in both dissection and in the study of sections, that there is no close or organized connective tissue enclosure of the ureter here (figs. 4 and 5 ). The reflecting muscle fascicles show the same loose, poorly organized investment of connective tissue as the bladder does generally.

The deeper plane of bladder muscle in the region of penetration of the ureter is composed mainly of longitudinally running muscle fibers but with many intermingled, oblique, and criss-crossing bundles (fig. 3). This deeper plane has been described as largely fascial in nature ("sling" fascia, Hutch et al., '61). It ap- pears in my material to be as much muscle as the superficial layer. With regard to the concept of a sheath, it should be emphasized that connective tissue is not conspicuous in the region. In fact one is impressed by its relative scantiness and delicacy.

The literature contains confusions and contradictions concerning the detrusor fascicles which reffect onto the terminal ureter. Urological reports are replete with references to Waldeyer's sheath and some authors refer this sheath to the ureteric musculature and also carry it inside the bladder. Waldeyer himself in 1892 in a brief report concerning the relations here acknowledged the previous Handbuch descriptions of detrusor fibers reflecting onto the lower part of the ureter. Waldeyer added to this information the fact that there is an injectable space under this musculature which allows the layer to be easily separated from the ureter in a $1 / 2$ 
to $3 / 4 \mathrm{~mm}$ wide separation as far as approximately $3 \mathrm{~cm}$ up on the ureter. He stated that the space is to be likened to a lymphatic separation. Waldeyer's use of the term "ureterscheide" has apparently lead to a translation of "sheath" for this structure and, there has been a gradual transference of meaning to a more encompassing connective tissue enclosure different from the originally described reflection of detrusor muscle fascicles. Wesson in 1920 used the term "Waldeyer's ureteral sheath" and spoke of a sheath origin for Bell's muscle and other muscle

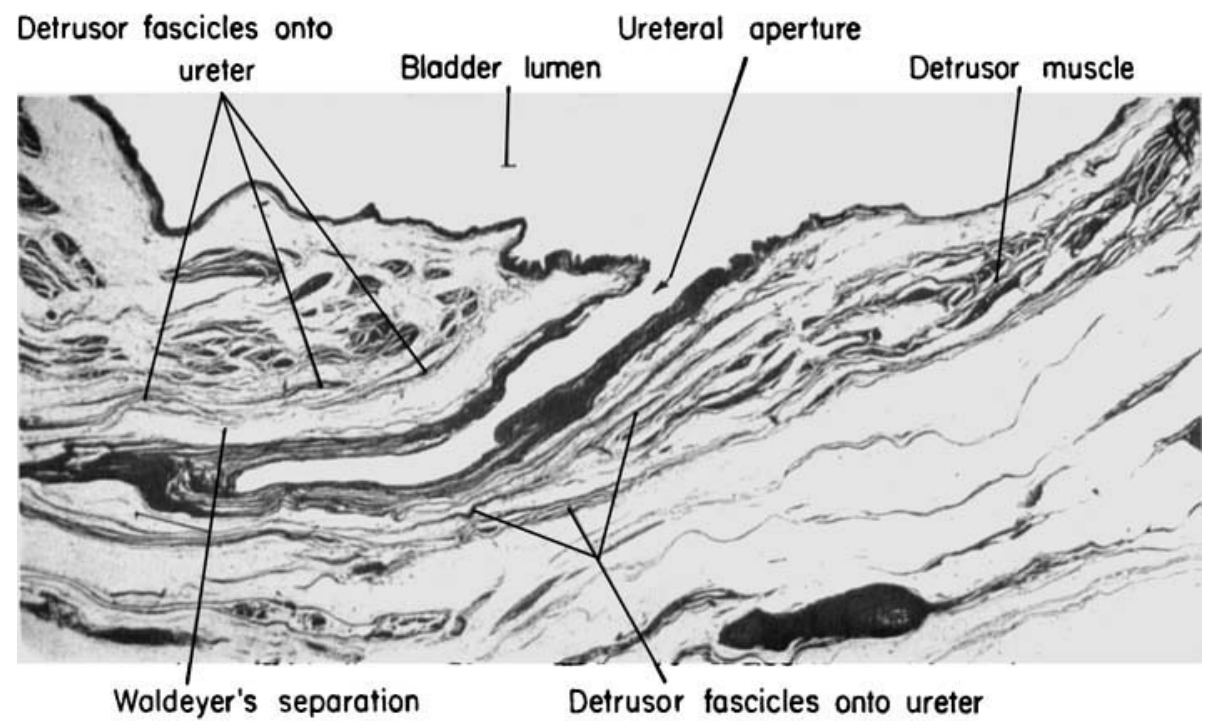

Fig. 4 Photograph of a section longitudinal to the intramural ureter. Masson trichrome stain. Human, $x$ 13. (By permission of the Journal of Urology.)

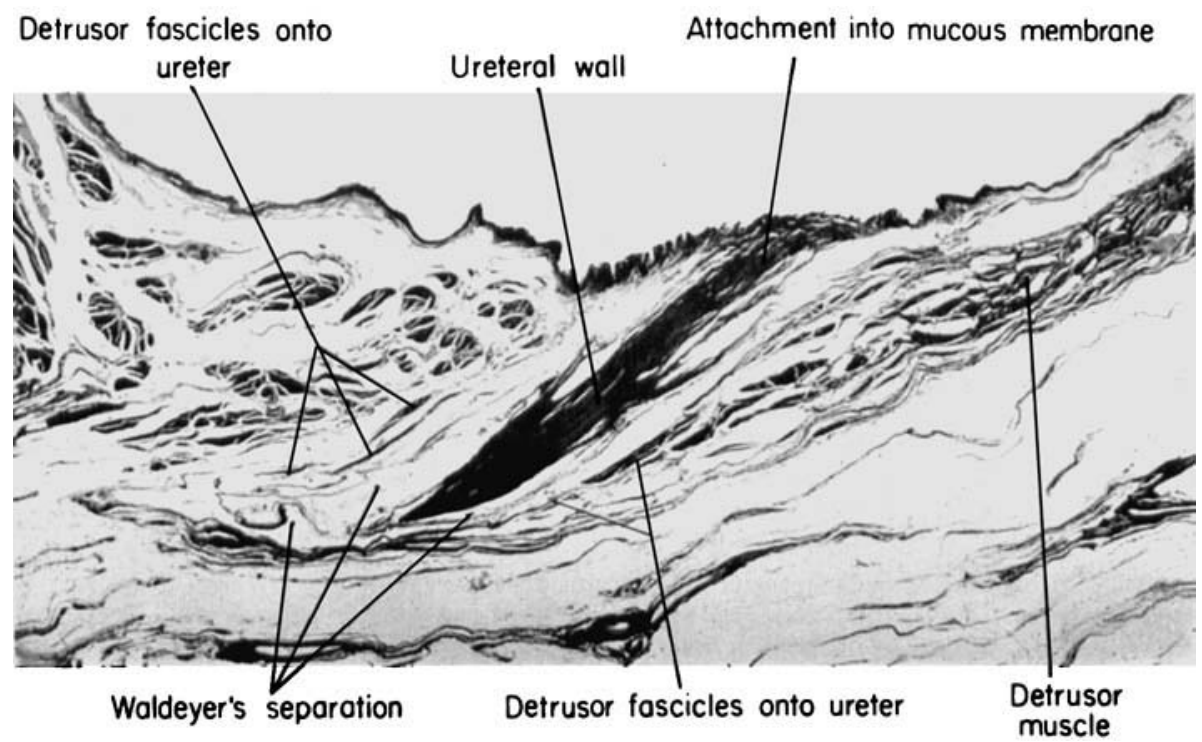

Fig. 5 Photograph of a section through the long axis of the terminal ureter. Masson trichrome stain. Human, $\times 13$. (By permission of the Journal of Urology.) 
bands of the trigone. More recently Hutch described the sheath in relation to surgery of the ureterovesical junction. He emphasizes the fixation of the ureter to the bladder wall by the sheath at this point and attributes the stability of the junction to the reciprocal attachment of these structures. Tanagho and Pugh ('63) have described "Waldeyer's sheath" in great detail. They state that the sheath forms an encircling layer around the lowermost one and one-half to $3 \mathrm{~cm}$ of the ureter and consists histologically of fibromuscular tissue. They note that it blends with the adventitia of the extravesical ureter, but go on to state that "dissection of the intravesical part shows that the sheath follows the ureter through the ureteric canal again forming a complete encircling fibromuscular layer around the ureter." These authors state, in some contradiction to others, that they conceive of the sheath as a structure of ureteral origin which fuses with the outer layer of the ureter at its upper end and is attached at its lower end to the trigone, forming the middle trigone layer. In this statement they are in opposition to virtually all previous workers who have found these fascicles to be a reflec- tion of bladder wall musculature, especially its superficial layer. I am unable to confirm the Tanagho and Pugh statement nor do I find that the sheath is prolonged inside the bladder. Neither do I attribute to the sheath the principal fixation of the ureter at its entrance through the bladder wall as Hutch does. Indeed sections through the region of the ureterovesical junction (figs. 4 and 5 ) show very clearly that detrusor fascicles do reflect onto the terminal ureter but equally clearly show that they do not form a close investment of the tube. Such sections confirm Waldeyer's statement concerning an injectable space between these reflecting fibers and the wall of the ureter, so that the term "Waldeyer's separation" (which is the first meaning of the term "scheide") is confirmed in my studies. Contrary to the concept of fixation here one must in fact think of a looseness and freedom of penetration as the ureter goes through the bladder wall. Because of the usual connotation of the term "sheath," it should perhaps be emphasized that there is no concentration of fibrous tissue in the junction region. The detrusor fascicles of bladder wall which reflect onto the ureter carry

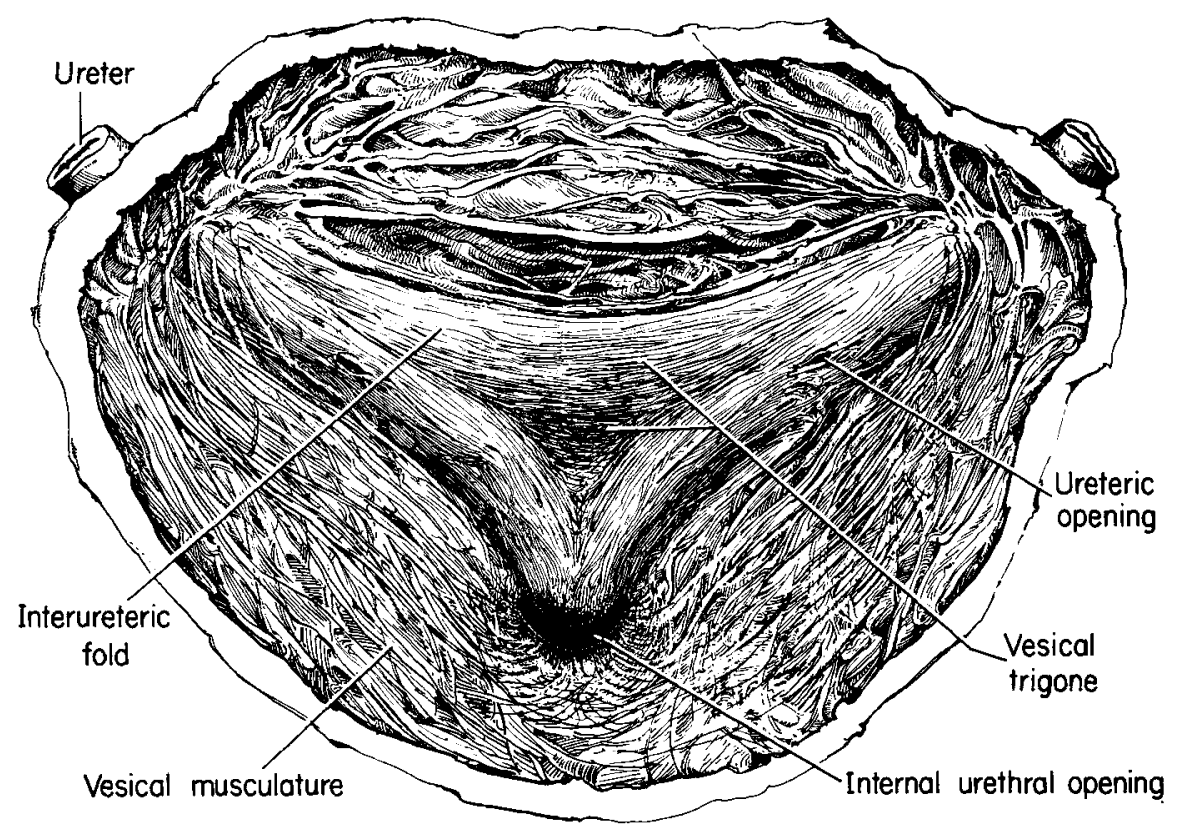

Fig. 6 Interior of posterior-inferior portion of bladder; vesical trigone, ureteric and urethral apertures. (By permission of the Journal of Urology.) 
with them the scanty areolar tissue which is characteristic of bladder wall but there is no close fibrous tissue investment of the terminal ureter. If the term sheath is to be applied, it must refer primarily to the reffection of detrusor muscle.

Terminally, the ureter loses the layering which is typical of it through most of its course. Here the ureteric muscle becomes primarily longitudinal (fig. 5), is finely fasciculated and is intermingled with connective tissue. The ureter is readily identifiable and separable from the bladder muscle, the ureter exhibiting fine fasciculation and a close relationship with connective tissue whereas the detrusor exhibits coarse fasciculation and scanty connective tissue. Further, elastic tissue which is not represented strongly at any level of the ureter above the bladder begins to increase just outside the bladder and is more prominent intramurally. The intramural and intravesical parts of the ureter total about $1 \frac{1 / 2}{\mathrm{~cm}}$ in length. Of this length one-half or slightly more is intravesical and submucosal (fig. 6). As indicated above, the ureter passes through the bladder wall well separated from the bladder wall itself.

\section{Vesical trigone}

The vesical trigone is ureteric in nature, representing the continuation and termination of the ureteric musculature within the bladder. The trigone form is produced by the blending of the ureteric musculature of the two sides across the midline forming the interureteric fold, together with an extension of the lateral part of the ureteric muscle downward toward the vesical aperture. There is a fanning out here of the ureteric musculature through the entire triangular area but the greater part of its substance passes directly medially and intermingles with that of the opposite side to produce the interureteric fold of the trigone (fig. 6). A vertical section of the trigone area through the posterior wall of the bladder (fig. 7) clearly shows that the ureteric muscle is condensed into a band which is the interureteric fold and is dispersed in scattered fascicles inferior to the fold, all internal to the more massive musculature of the bladder wall. The ureteric musculature which passes towards the

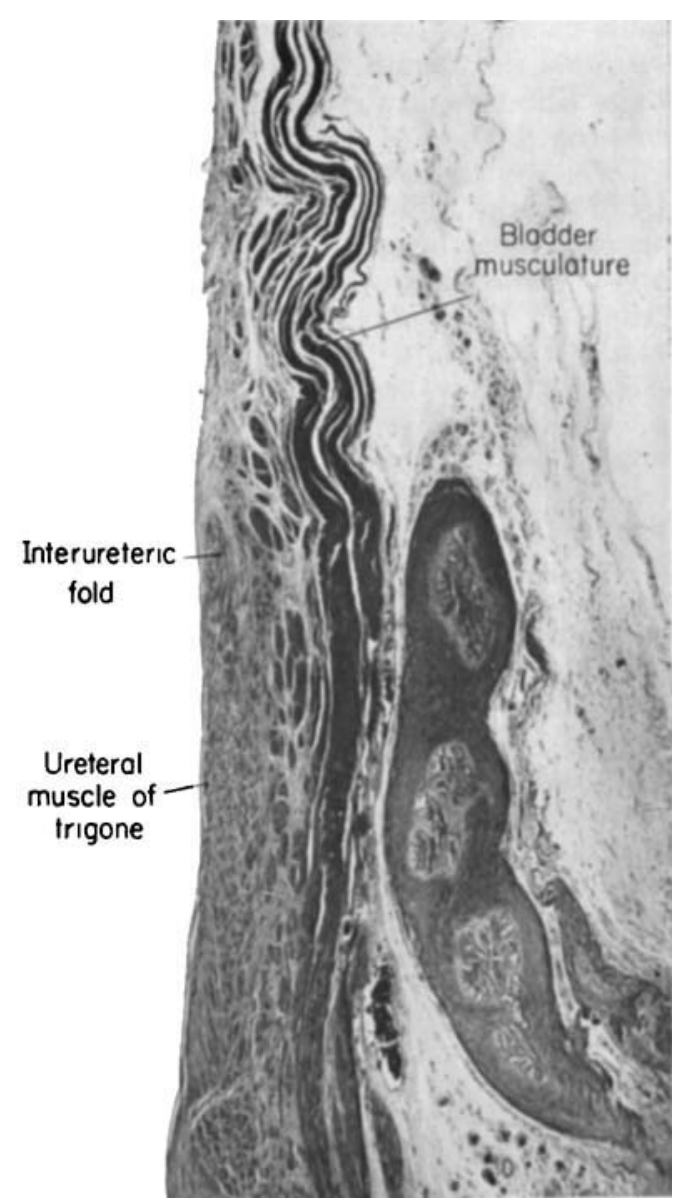

Fig. 7 A vertical section of a part of the posterior wall of the human bladder through the vesical trigone. $\times 15$.

vesical opening is less in amount than that which passes from side to side and very few of the fibers of this muscle actually descend in the urethral wall. Examining the intravesical part of the ureter it would appear that the musculature flattens out and rolls under and allows the lumen of the ureter to migrate to the surface (fig. 8). Some of its fine fibers decussate just proximal to and also distal to the ureteral aperture but the wall of the ureter becomes progressively thinner over the lumen until the aperture is reached (fig. 8). The disposition of the ureteral musculature provides for a firm attachment. The ureteral muscle attaches very firmly to the mucous membrane of the bladder throughout the trigone region (fig. 5). 


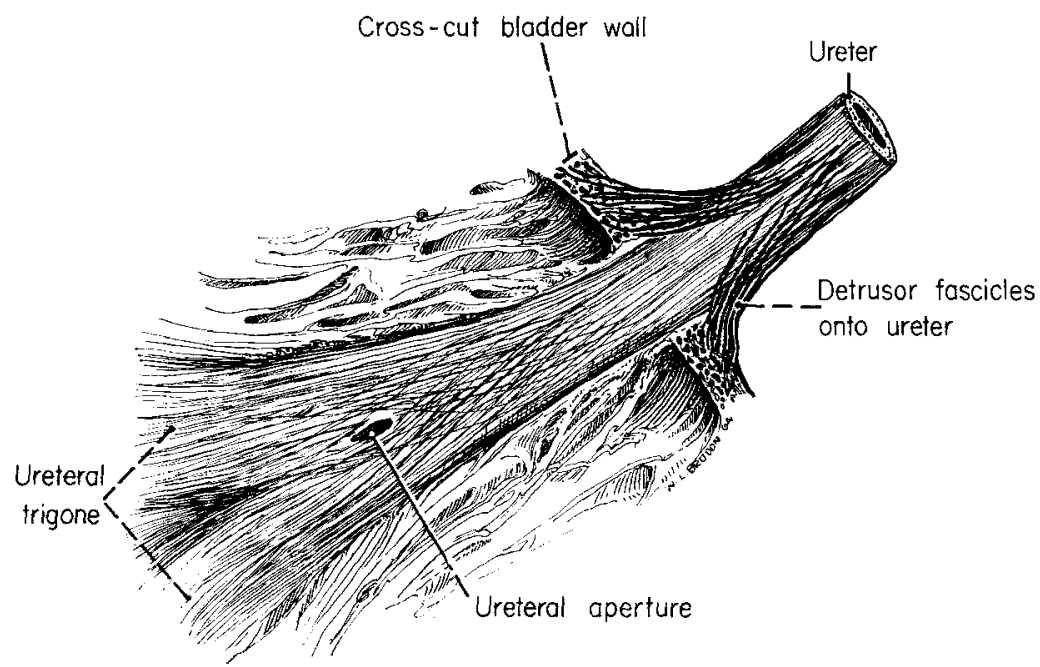

Fig. 8 Detail of dissection of extramural and intramural ureter, from within. (By permission of the Journal of Urology.)

This accounts for the well accepted smoothness or lack of folding of the mucous membrane here (fig. 5). Ureteric muscle also attaches into the muscular bladder wall deep to the trigone area. One gains the impression that these attachments are the ultimate and important fixations of the ureter. The ureteric muscle blends firmly here with the substance of the bladder both in its mucous membrane and its musculature and intermuscular connective tissue (fig. 7). With this firm attachment of the ureter into the vesical trigone region of the bladder, there is no need for a fixation at its passage through the wall, and indeed, expansion of the bladder is aided by a looseness in this region. The detrusor fascicles reflecting onto the ureter therefore are not to be thought of as the primary fixation of the ureter, and the region of penetration is to be regarded as free.

\section{LITERATURE CITED}

Cunningham, D. 1964 Textbook of Anatomy, tenth ed., London, Oxford Univ. Press.
Henle, J. 1856 From Von Mollendorf.

Hunter, de W. T., Jr. 1954 New concept of urinary bladder musculature. J. Urol., 71: 695-704.

Hutch, J. A., R. D. Ayres and G. S. Loquvam 1961 The bladder musculature with special reference to the ureterovesical junction. $J$. Urol., 85: 531-539.

Sappey, C. 1889 From Von Mollendorf.

Tanagho, E. A., and R. C. B. Pugh 1963 The anatomy and function of the ureterovesical junction. Brit. J. Urol., 35: 151-165.

Uhlenhuth, E., de W. T. Hunter, Jr., and W. E. Loechel 1953 Problems in the Anatomy of the Pelvis. J. B. Lippincott Co., Philadelphia.

Von Mollendorf, W. 1930 "Der Exkretionsapparat" in Handbuch der Mikroscopischen Anatomie des Menschen, VII, 1, Springer, Berlin, p. 279-292.

Waldeyer, W. 1892 Ueber die sogenannte Ureterscheide. Anat. Anz., Verhandl. d. Anatom. Gesellsch. in Wien, Juni, S. 259-260.

Wesson, M. B. 1920 Anatomical, embryological, and physiological studies of the trigone and neck of the bladder. J. Urol, 4: 279-317.

Woodburne, R. T. 1960 Structure and function of the urinary bladder. J. Urol., 84: 79-85.

- 1961 The sphincter mechanism of the urinary bladder. Anat. Rec., 141: 11-20.

- 1964 Anatomy of the ureterovesical junction. J. Urology, 92: 431-435. 